International Review of Research in Open and Distributed Learning Volume 19, Number 3

July - 2018

\title{
Effects of Open Textbook Adoption on Teachers' Open Practices
}

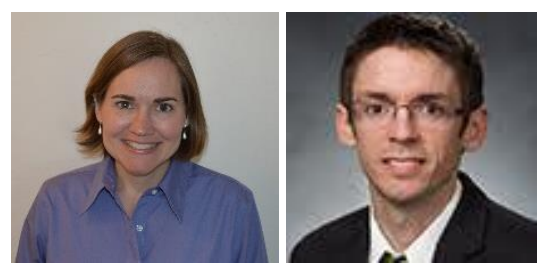

Stacie L. Mason and Royce Kimmons

Brigham Young University

\begin{abstract}
The purpose of this qualitative study was to understand whether certain theoretical benefits that open educational resources (OER) might have on teacher practice were being realized by a group of secondary teachers using open science textbooks. In surveys and interviews, teachers were asked to describe their classroom practice before and after adopting an open textbook, including practices relating to openness. Teachers were also asked to rate the quality of open textbooks they were using in contrast to textbooks used previously. Most participants reported changes to practice, and the most commonly cited changes could be attributed to a combination of openness and online format. For example, participants described linking textbook content to other online resources. In comparisons of current to previous practice, however, teachers did not report increases in the open practices of collaboration, revising, or adapting.
\end{abstract}

Keywords: textbooks, open education, educational practices, open pedagogies, open educational resources, OER 


\section{Introduction}

For K-12 teachers in the United States, finding textbooks that fully meet their needs can be challenging. Some textbooks are not adequately aligned to state standards, as publishers do not create separate versions for varying standards. Although Common Core standards are used in 42 states and four territories, textbooks labeled as "core aligned" may not actually be well-aligned; standards alignment may be tacked on afterwards and not integrated intentionally in the design (Common Core State Standards Initiative, 2016; Polikoff, 2015; Stern \& Roseman, 2001). Some textbooks that do align with the standards may not be developmentally appropriate or adequate in differentiated instruction for individual student needs.

With commercial instructional materials not meeting teacher and student needs, some schools are turning to open educational resources (OER), defined by UNESCO (2016) as "any type of educational materials that are in the public domain or introduced with an open license" (para. 1). Many proponents of open textbooks note three potential benefits: (a) cost savings, (b) increased access to quality content, and (c) teacher empowerment or improved professionalism (Kimmons, 2016; U.S. Department of Education, 2015).

First, as OERs can be freely copied, used, and shared, they tend to cost less than commercial resources. Wiley, Hilton, Ellington, and Hall (2012) found that open textbooks could save schools $50 \%$ or more over commercial textbooks. With shrinking state budgets, lower cost is a compelling issue (Hilton III, Larsen, Wiley, \& Fischer, 2016); however, using OER does not guarantee cost savings, as the previous study also showed that having teachers print small numbers of thick textbooks costs more than buying commercial books. Additionally, developing and supporting openly licensed resources is costly. Furthermore, reducing costs might not be a sufficient reason to replace commercial materials with OER. Administrators have reported that quality and features influenced their purchasing decisions much more than cost (K12 Handhelds, 2015).

Thus a second advantage, increased access to high-quality instructional materials, may be more important than lower expense. OER can be adapted - updated, improved, and tailored to the needs of schools and individuals - their use in schools with low budgets thus improves equity. However, not all OER are high quality, and identifying quality resources can be more difficult than trusting commercial textbook companies. Most secondary science classrooms use commercial textbooks, and selection processes vary among states, districts, and even within districts (K12 Handhelds, 2015). Prospective users must know enough about both commercial and open texts to efficiently judge their quality.

Third, OER use can empower teachers as they adapt resources to meet student needs. Kimmons (2016) has identified three main professional benefits of openness with OER: (a) supporting professional collaboration, (b) connecting teachers and students to a global community, and (c) allowing teachers to create content. However, administrators may discourage teachers from changing approved instructional materials; teachers may lack time, inclination, or knowledge to adapt resources; and teachers desiring to adapt OER need the support and trust of administrators. Thus current power structures and expectations 
placed on teachers might not be amenable to teachers becoming active in curating, adopting, and adapting resources.

Likely due to its perceived benefits, use of OER in the United States is increasing. Since the U.S. Department of Education (2015) launched its \#GoOpen campaign in October 2015, at least 91 districts and 19 states have committed to using openly licensed resources (Office of Educational Technology, n.d.). Through \#GoOpen, districts commit to replacing at least one textbook with an open resource, and states commit to using OER, developing and maintaining an OER repository, and sharing resources with other \#GoOpen states (Office of Educational Technology, n.d.).

At present, the potential benefits of K-12 OER use are mostly theoretical; currently very few studies have published data indicating whether potential benefits are being realized in K-12 settings. Most published OER research has focused on higher education, but separate K-12 studies are needed for the significantly different contexts. This study will contribute to the OER research base by examining the benefits realized by a group of secondary teachers using open science textbooks.

Three research questions guided this study:

1. How has using an open science textbook affected practices related to textbook use?

2. How and how extensively have teachers used the open practices of revision and collaboration?

3. How have teachers valued the open textbook used?

\section{Literature Review}

The 2012 National Survey of Science and Mathematics Education reported that most science teachers used commercial textbooks, rated them positively, and supplemented them with other resources (Banilower et al., 2013). Early studies have indicated that K-12 teachers not using commercial textbooks can use open textbooks effectively (Wiley et al., 2012; Robinson, Fischer, Wiley, \& Hilton, 2014; Hilton et al., 2016). Among the earliest published research on U.S. K-12 open textbook use, Wiley et al.'s (2012) study of 20 middle and high school science classes found no significant difference between standardized test scores of students using open or commercial textbooks. In a follow-up study, Robinson, Fischer, Wiley, and Hilton (2014) found that students using open textbooks in secondary science classes scored slightly higher than students using traditional textbooks. A new study comparing mathematics test results of elementary school students using OER and commercial resources found no significant difference (Hilton et al., 2016. In all three studies, outcomes for OER use, including cost and student test scores, were comparable to or better than outcomes for conventional materials. 
In an international study of K-12 teachers' usage and perceptions of OER, most reported that OER helped them meet diverse needs, differentiate instruction, personalize instruction, provide broad coverage of curriculum, reflect on their teaching, and increase subject knowledge and that OER increased student independence, self-reliance, satisfaction, and engagement (de los Arcos, Farrow, Pitt, Weller, \& McAndrew, 2016). In Kimmons' (2015) study of perceived textbook quality, 30 K-12 teachers evaluated open/adapted textbooks $38 \%$ higher than commercial textbooks (significantly higher on all 10 criteria), and $16 \%$ higher than open (non-adapted) textbooks.

Though in early phases, OER awareness, usage, and research are increasing, revealing varied benefits and challenges. In their 2013 evaluation of the state of the OER ecosystem, The Boston Consulting Group reported the movement has momentum, though still far from mainstream. Study participants $(n=165)$ indicated their top two reasons for adoption were flexibility and low cost, and their greatest challenges were finding quality materials, especially for non-STEM subjects, and remixing and revising materials to make them useful. Additionally, Baker, Asino, Xiu, and Fulgencio (2017) found that digital divides and student preferences toward textbooks also play a role in how OER are used in K-12.

Given these challenges to implementing OER, sustainability is a significant issue. In a summary of K-12 adoption and implementation practices, K12 Handhelds (2015) concluded that districts purchasing K-12 instructional materials were more concerned with quality than price, and additional features, "such as customization, assessments, data gathering and analysis, and professional development," were "essential to adoption" (p.1). In survey responses, K-12 administrators showed ambivalence about open practice and the perceived benefits of open licensing. Butcher and Wilson-Strydom (2008) suggested that OER development and implementation should be successful if teachers choose to adopt open textbooks; are involved in the adoption; and are provided time, training, and compensation to produce high-quality textbooks. Wiley, Webb, Weston, and Tonks (2017) take this one step further and argue that long-term sustainability of OER may be best achieved by empowering students (rather than teachers) to become the creators and remixers of OER. Another way to increase sustainability may be to focus on theoretical benefits beyond cost.

While one of the major selling points of OER is its low cost to users, the cost of adopting open textbooks may vary significantly depending on the adoption model (Wiley et al., 2012). Kimmons (2016) has argued that stakeholders should focus less on cost and more on benefits such as collaboration, differentiation, and professionalization. Similarly, various researchers have called attention to flexibility, learner-centered education, collaboration, knowledge sharing, and ongoing quality improvement (Bliss \& Patrick, 2013; Butcher \& Wilson-Strydom, 2008; Tonks, Weston, Wiley, \& Barbour, 2013). While these perceived benefits have been primarily theoretical, they seem a logical outgrowth of the ideals of openness associated with OER.

Remillard (2005) has characterized the teacher-curriculum relationship as "a participatory relationship between the teacher and the curriculum" (p. 236). In short, to be successful, teachers need alignment of curricula with their underlying teaching philosophies and support in learning new materials (Remillard, 
2005, p. 239; Taylor et al., 2015). Based on these assertions, we might expect teachers who choose to adopt open textbooks to agree with a philosophy and classroom practice of openness, such as collaboration, knowledge sharing, and ongoing quality improvement. Drawing and building on previous research regarding the implications of openness (Kimmons, 2014), this study explored whether a group of teachers who were adapting and using open textbooks were experiencing these benefits.

\section{Method}

In summer 2015, secondary science teachers from a pilot school district were brought together by the University of Idaho Doceo Center to adapt openly licensed science textbooks from CK-12, a non-profit foundation that provides free open online textbooks and other instructional resources (CK-12 Foundation, 2017). The following summer, 36 teachers from throughout a western state met for a five-day institute to update and adapt open science textbooks to use in their classrooms in the coming fall semester. The teachers met in small groups based on their courses of instruction and used textbooks provided through the CK-12 Foundation. After this institute, participants continued working with technical and resource support from the support center; 26 secondary science teachers participated in this study using openly licensed science textbooks that they had helped to create.

\section{Participants}

Participants were teachers in Grades 7-12 who had adapted and adopted openly licensed textbooks in five subjects: biology, chemistry, earth science, life science, and physical science. Their teaching experience was varied: $38 \%$ with $0-5$ years and $31 \%$ with more than 15 years. All junior high and high school grade levels were represented, and there was a fairly even distribution by grade. Most teachers reported that students accessed their textbooks online: $40 \%$ used online only, $44 \%$ used both print and online, and $16 \%$ used print only.

\section{Research Design}

The current "basic qualitative study" was designed "to understand how people make sense of their lives and their experiences" (Merriam, 2009, p. 23). This seemed to be the most appropriate approach because our sample consisted of a relatively small group of practicing teachers and our desire was to understand (in their own words) how using the open science textbook had affected their practice. We collected data through surveys and interviews. We began with surveys to get a general sense across the teachers of how their practices had changed and to gather open responses on their experiences. Though we used a survey to collect initial data and to provide descriptive results of our sample, we analyzed the data in a qualitative manner (e.g., non-generalizable, non-inferential). We then did follow-up, semi-structured interviews with five teachers to dig deeper into issues that emerged from the survey. Data collection, including surveys and interviews, took place from January to April 2017 after most participants had used the resource for a full semester. Though results may be unique to teachers in a particular western state, we have provided 
extensive detail in the teachers' own words to allow readers to determine the transferability of results to other contexts.

\section{Instruments}

The survey designed for this study included varied questions about participants' classroom practice, textbook use, and perceptions. Questions about OER usage and classroom practice were modeled after the 2012 National Survey of Science and Mathematics Education (Banilower et al., 2013). For efficiency, most questions were based on a 5-point Likert scale. Items included two constructs of 15 items, each with Cronbach's alphas of .908 and .932 respectively, suggesting high internal reliability. A few additional questions solicited open-ended responses to allow detail, variety, and complexity in responses. At the end of the survey, participants were asked whether they would participate in a follow-up interview.

For these semi-structured interviews, we created a question bank aligned with the research questions guiding the study, modeled after examples of effective interview questions from Merriam (2009). Based on the participants' survey responses, the lead researcher compiled an individualized set of relevant questions for each interviewee and conducted a 10-30 minute interview via video conferencing.

\section{Data Analysis}

We used descriptive statistics to identify general patterns in the data regarding teachers' ways of using open textbooks, changes in practice since implementing them, and perceptions of them. For open-ended questions, the lead researcher used content analysis to generate themes, sorted survey responses into categories, and selected five participants who were willing to be interviewed. We transcribed, coded, and classified interview responses, preserving interviewee confidentiality by assigning each a non-gendered pseudonym (Table 1). Initially we used line-by-line coding for critical data analysis; in vivo codes emerged from reading the data, to which we added focused codes to refine, synthesize, and make sense of the data (Charmaz, 2006). During analysis we looked for relationships between open textbook use and classroom practices.

Table 1

Interview Participant Demographics

\begin{tabular}{llcc}
\hline Pseudonym & Textbook & Grade level & Years of teaching \\
\hline Alex & Biology & 10 & $11-15$ \\
Bailey & Life science & $7-8$ & $11-15$ \\
Chris & Life science & 7 & $6-10$ \\
Dana & Earth science & 8 & $0-5$
\end{tabular}




\section{Results}

\section{Survey Results}

Of 29 survey responses received, three were excluded because only background information had been provided (e.g., grade taught, number of years taught, textbook used). The survey included branching so that participants did not see all of the questions, and respondents were not required to answer every question; therefore, a number of responses varied slightly among survey items.

Classroom practice. Several survey questions related teachers' classroom practice to their current and previous textbooks (see Figure 1). Overall, respondents' practices were similar for both open and previous textbooks. Descriptive reports indicated they were slightly more likely to assign readings, questions, or activities from their open textbooks and less likely to skip sections of the open textbook, supplement the open textbook, revise or adapt the open textbook, or collaborate with colleagues or students to select or adapt instructional materials while using the open textbook (Figure 2). All reported changes were small (less than 0.5). The largest reported changes were decreased frequency of supplementing the textbook with outside readings or assignments and decreased revision or adaptation of textbook content. 


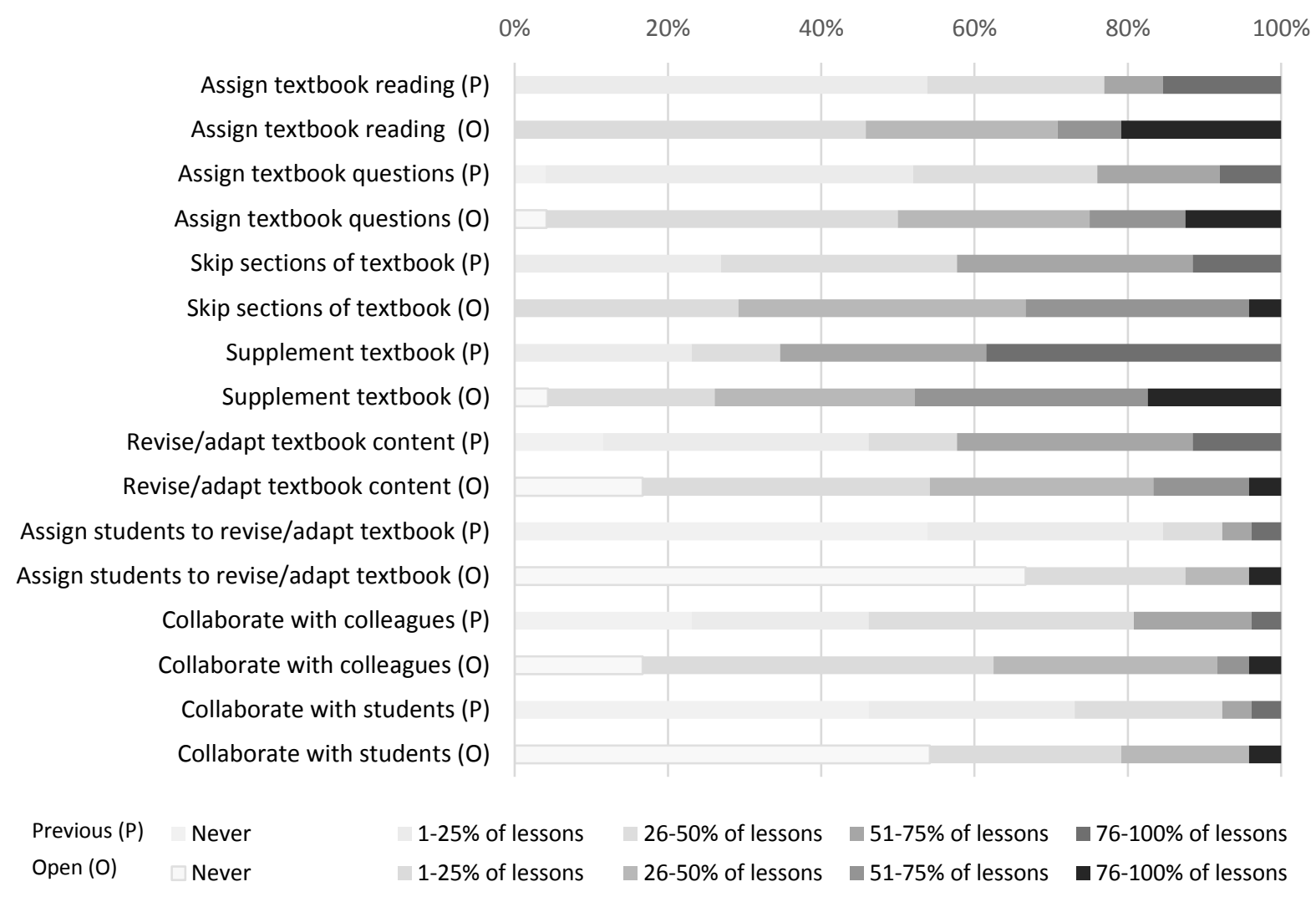

Figure 1. Frequency of certain classroom practices with the previous science textbook (top bar) and the current open textbook (bottom bar). 


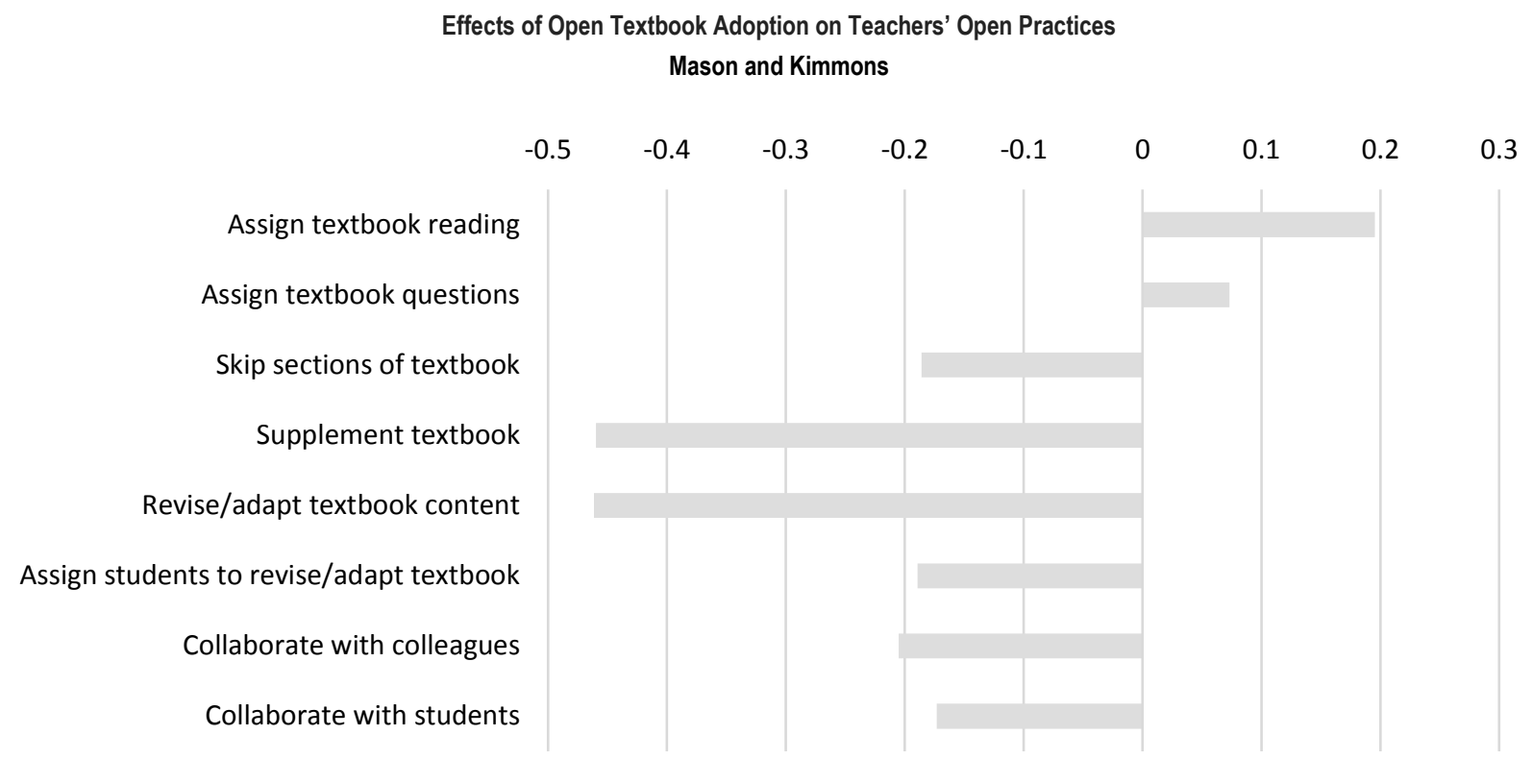

Figure 2. Comparison of frequency of certain classroom practices. Mean scores for previous textbook practice were subtracted from mean scores for open textbook practice. A positive comparison score indicates higher rates of the practice while using the open textbook; a negative score indicates higher rates of the practice with the previous textbook. The figure truncates the scale to show small differences in mean scores. The range of possible differences was -4 to 4 .

For a separate question, almost all respondents reported making changes to classroom practice after adopting an open textbook. When asked the extent of their alterations, $4 \%$ chose not at all, 35\% chose minimally, 39\% chose some, $19 \%$ chose considerably, and $4 \%$ chose almost entirely. Those who reported at least some changes were asked two follow-up questions. First they were asked, "What have been the most significant changes in your classroom practice since you adopted an open textbook?" Of 13 total responses, two mentioned changes related to format: "Less printing" and "Using more online." Three responses mentioned changes attributable to openness and quality: "I don't need to skip around in the book and skip sections because the book is in the order I teach and includes the information my students need. There isn't a bunch of extra stuff," "More efficient coverage of required topics," and "Assigned more reading." Five responses mentioned changes that could relate to both format and openness: "Easier to use the best of all resources available," "The use of technology which is built into the text . . . allows me to add videos and other resources," "Flexibility and the allowance of independent student research," "The ability to use other online resources in conjunction with the text," and "I can incorporate materials I want [students] to have directly into the text." Two responses mentioned changes pertaining to preparation and expectations: "Less time prepping" and "No need or push to use adopted purchased textbooks." Two responses related to changes in outcomes, with format and openness as the most common contributing factors.

Respondents were also asked, "Which factors do you think most influenced you to change your classroom practices since adopting an open textbook?" The factors they ranked most influential were "involvement in the OER summer institute," "textbook format (online)," and "other training (not related to OER)." The 
factors ranked lowest were "school or district mandates," "life events/personal factors," and "textbook content."

Participants reporting their changes as minimal or not at all were asked why they had made few changes. Of nine respondents, $67 \%$ chose "I didn't need to," $11 \%$ chose "I can't think of any changes I would like to make," and 22\% chose "other" - specifying "I started the year off with a traditional text and need to work time into re-writing the curriculum" and "lack of tech to effectively implement." Most respondents who made minimal or no changes indicated that changing to an open textbook did not require significant changes to their practice.

Most respondents reported that time for preparing to teach was about the same with the open textbook as with their previous textbook; none required more preparation time. Respondents who reported spending less preparation time noted, "I don't have to find as many supplemental resources," "I know this textbook better, but still have to find age app[ropriate] activities," "I trust that the reading is up to date. Previous textbooks were printed in 1999," and "It is easier to put material in each section (easy to find)."

Perceptions of quality. Overall, respondents rated both their open textbook and their most recent non-open textbook favorably but rated the open textbooks higher by a ratio of 3:1 (77\% vs. 23\%). Participants were asked to indicate their level of agreement with 15 separate statements about the quality of their current open textbook and their previous non-open textbook. Most respondents agreed with most of the statements for both (see Figures 3 and 4). They rated their non-open textbooks slightly higher on two measures: alignment to assessments and providing teacher support (see Figure 5). Regarding inclusion of differentiation strategies, mean scores were equal for open and non-open textbooks. For the other 12 measures participants rated their open science textbooks higher than their previous, non-open textbooks. The categories in which respondents indicated the largest differences in perceived quality were alignment to state standards and likelihood of recommending the book to other teachers. 
Effects of Open Textbook Adoption on Teachers' Open Practices

Mason and Kimmons

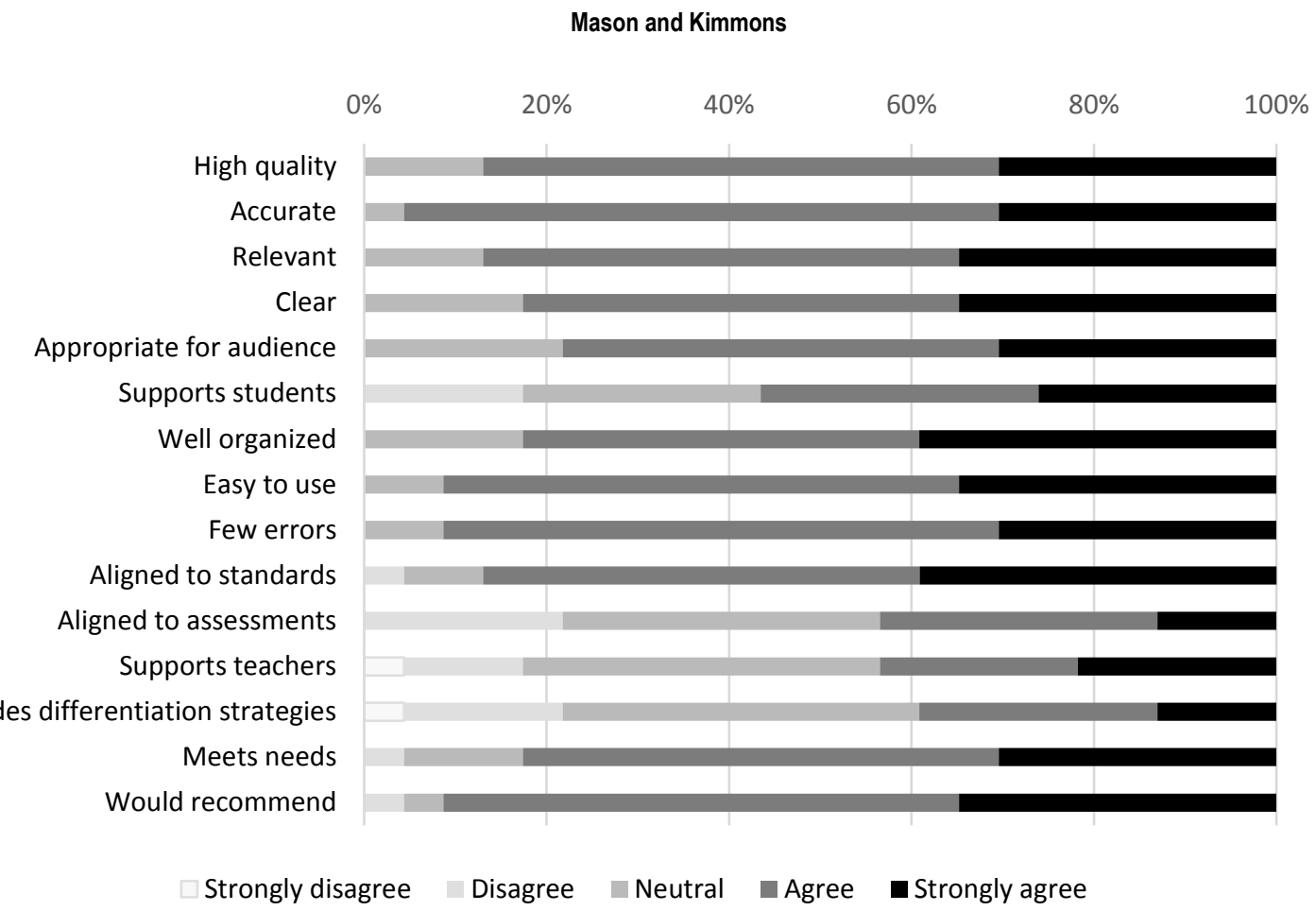

Figure 3. Perceived quality of open science textbooks.

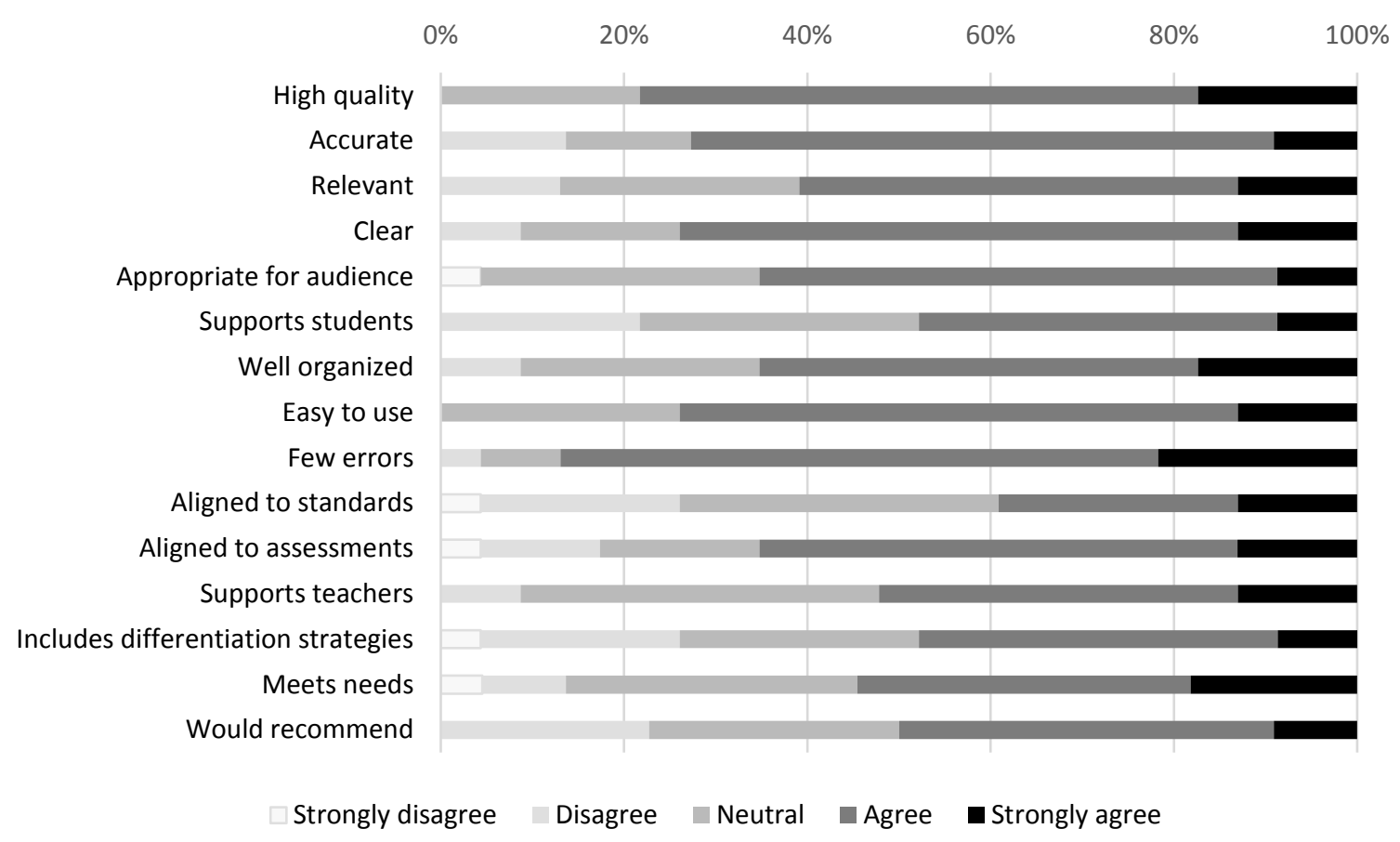

Figure 4. Perceived quality of non-open science textbooks. 


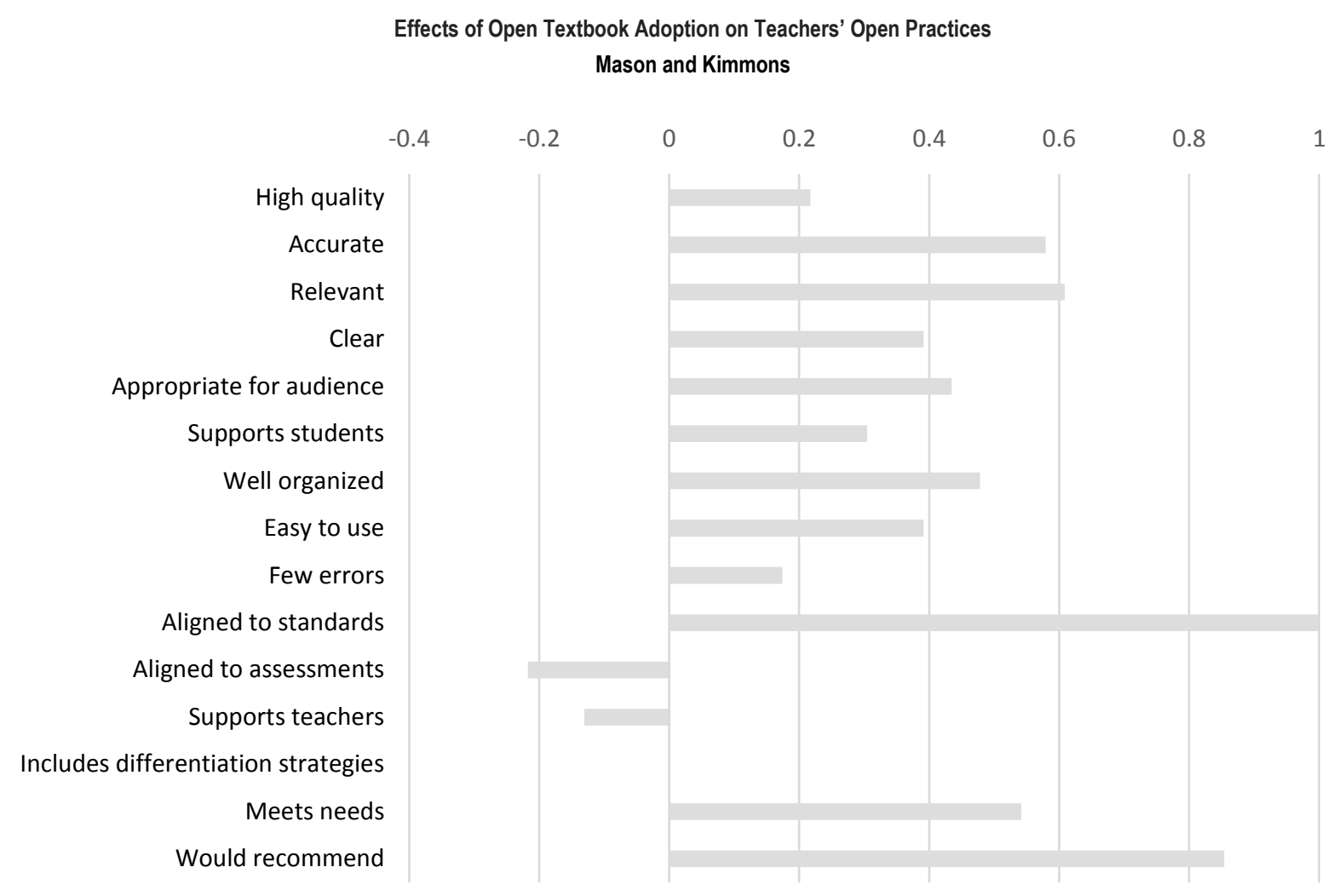

Figure 5. Comparison of perceived quality of open and non-open science textbooks. Mean scores for previous textbooks were subtracted from mean scores for open textbooks. A positive comparison score indicated that teachers rated the open textbooks higher than non-open textbooks; a negative comparison score indicated that teachers rated their non-open textbooks higher. The figure scale was truncated to show small differences in mean scores. The range of possible differences was -4 to 4 .

Most respondents who preferred their previous textbook indicated that it was of higher quality, while one noted a problem with accessing the open textbook. Those preferring the non-open textbook were more likely than the total sample (a) to have used print-only versions of the open textbooks and (b) to have reported only minimal changes to classroom practice; however, the number of participants who preferred the nonopen textbook was too small $(\mathrm{n}=5)$ for a meaningful comparison.

\section{Interview Results}

The five participants interviewed used three of the five textbooks and had varied teaching experience.

Classroom practice. Two of the three research questions relate to classroom practice. In interviews, the lead researcher asked participants to describe their transition from non-open to open textbooks, their experience with using open textbooks, and their changed classroom practices.

Transition to open. Interviewees described their shift to an open textbook as fairly smooth. Dana said, "Kids didn't really get used to it for about a month, and then they got used to it, then it went fine." Participants' changes related primarily to the online format. Alex noted "a little bit of a change," but 
the district having adopted iPads the year before "made that transition a little bit smoother." Similarly, Chris explained,

We've had iPads in the classroom for 4 years now. . . . So 4 years ago I switched to using ... all kinds of apps and ... online resources. ... Now that I have a[n open] textbook ... I haven't changed my teaching-because I've been using open ed sources for 4 years.

Textbook use. About three-fourths of survey respondents said they used their textbooks in fewer than half of their lessons; teachers interviewed likewise described limited textbook use. When asked to mention a classroom practice that had not changed with open textbooks, Alex noted,

[M]y instruction doesn't revolve around the textbook in any way, shape, or form. But I do think that it's a resource, and a lot of kids don't take advantage of it. . . I I still ask them to read, and now I can ask them to do some highlighting.

Eddie reported increased but still limited use: "I still don't use [the open textbook] a ton ... but I definitely use it more than ... our old textbooks. And I plan to use it even more next year."

Over several years of teaching, Chris had observed diminishing textbook use:

[I]t's supplemental material.... I think when we had a paper textbook, [we] relied on that textbook and the supplemental material ... to teach those things. And with open ed resources, I rely on my textbook this much [showed thumb and finger about an inch apart], and I use other resources as well.

Changes in practice. Multiple teachers noted changes in their ability to link textbook content to other resources, but perceived the significance of those changes differently. An interviewee who in the survey had reported only minimal changes to classroom practice commented that one of her main changes was being able to link assignments to questions and other resources. An interviewee who had reported considerable changes similarly reported that the most significant change was that she could incorporate additional materials directly into the text.

Openness. When asked whether changes in classroom practice had more to do with the online format of the textbook or its openness, Alex pointed out the interrelationship of the two:

I don't think that you get one without the other. Well, I guess you could have the online stuff without the open.... [T] he fact that we can give them current information is huge.... When I put links into articles, it would be links to things that are current for right now.

Thus openness with the online format allowed teachers to adapt books to keep textbooks up-to-date and meet specific needs. 
Revising and adapting. Participants recounted various approaches to revising and adapting open textbook material. When asked for an example, one teacher mentioned direct revisions to the textbook. Alex specified,

adding articles in, or adding different links in, rewording questions that may be misleading or unclear, changing just the general order ... looking at the textbook and thinking about what makes sense ... or updating information.

Eddie described making slideshows from the material, and Chris discussed making YouTube playlists "to use along with the book."

While the flexibility to alter open textbooks was generally considered an advantage, those who felt no need to do so were grateful for open textbook completeness. Interviewee Dana reported having revised or adapted a previous textbook but not open textbook material. When asked why, Dana explained, “[I] don't need to." When asked about future plans for revising or adapting the open textbook, Dana replied, "Maybe. If I get time. I don't have a lot of time."

All participants had been involved in revising and adapting their open science textbooks prior to adoption. While some survey responses mentioned revising and adapting textbooks, interviewees reported that they would wait until the summer to make changes. Chris said, “We don't mess with the textbook during the school year, even on an individual basis." Eddie expressed the desire to adapt material, but lacked time:

I would like to customize it just a little bit more for the information for my class ... [but] just didn't have time. Because what we cover may vary a little bit [from] what is covered in the text, and I want to be able to get rid of some extraneous information and add some in.

Alex mentioned other practical reasons to wait until the end of the year to revise:

I don't know how that works with what the kids have access to. And I know that we had a couple of technical issues when we were doing some editing and revising with it last summer because if it was shared at a certain point then those new edits didn't really show up.

Collaboration. Openness can promote collaboration; most survey participants reported collaborating with colleagues to select, revise, or adapt instructional materials. Eddie's example described significant, ongoing collaboration:

We meet once a week to talk about what we're doing overall between our classes. And I work especially with one of the other science teachers. Our classes are similar, so we mirror each other quite a bit, so we're always passing resources back and forth.

Collaboration requires time; Chris expressed appreciation for administrative support: 
We are continually collaborating for uniformity for all seventh graders so that they get the same general materials throughout. ... [O]ur district science department has been involved in lots of different grants over the last 4 years that have allowed us . . collaborative time. . . We've been so lucky.

When teachers have similar wants and needs, such collaborations tend to work well, but when teachers have conflicting opinions, the resulting textbook may reflect compromise rather than customized solutions to teacher's needs. Chris described both situations:

The first time it was just the teachers [from our district], and it was what we teach, and all the seventh grade teachers were there, and we designed the textbook based on our curriculum, based on our calendar, based on NGSS standards that we used, based on exactly what we did.... [The next year] a few of us ... helped the other people from the state edit the book that we designed and edited to meet, supposedly, everybody's needs.... So we're using version two this year, and I think some of us ... [feel], "No, we liked our book better." So we're going to go back and change it.

Dana, who helped produce an open science textbook for one subject but was using a different open textbook for a different science subject, regretted the difference: "The earth science book that we're using, it's not typically very streamlined, but I have access to a physical science book that's been very much streamlined." Open textbooks allow each teacher to customize, but most open textbooks represent collaborations—with compromises and some dissatisfaction.

Perceptions of quality. More than three-fourths of survey respondents preferred their open textbook to their previous non-open textbook. Four interviewees preferred the open textbook; one preferred the previous textbook.

Advantages. Interviewees affirmed open textbooks for flexibility, cost savings, accessibility, and independent learning.

Flexibility. When asked to describe the ideal science textbook, Eddie remarked,

I don't know if there is a perfect textbook because it would have to be different for every student. But the flexibility of this one is certainly appealing, and I like that it can be what I need it to be for different students.

Others agreed. Flexibility was the benefit mentioned most often: being able to revise and adapt the textbook.

Bailey expressed her preference:

[First] flexibility. Because ... I don't feel compelled to do the chapters in order. I just feel like I can jump around as I please. I also really like the different types of online resources that we attached to our content. 
Chris specified,

When you get a textbook ... you get 50 chapters and you use three.... I like the fact that [this book] is designed by us, it excludes anything that we don't need. It is short and sweet; it only has what we need.

When asked whether she would opt for an online open textbook or an online commercial textbook if given a choice, Alex affirmed, "I would definitely choose the open textbook, just for the ability to make those adjustments."

An interviewee who had indicated a quality preference for her previous non-open textbook, commented that she "would not go back to a non-open textbook." She elaborated,

You can't keep current with a printed textbook. That's the bottom line. . . And students now ... the way they learn is different. So you can't go back to a textbook. . . . It's just too [un]changing, too static. [Students] just don't like it. ... So I would never go back to a textbook.

Cost. Eddie began comments on advantages by saying, "It's a good resource; it's a free resource." Dana went further: "Our books are wearing out. . . . if I can use the budget that would normally go to textbooks for online stuff ... [I would have] more for my spending budget." When asked whether classroom practice would change if the district switched to commercial digital textbooks, Chris noted their appeal:

Some part of me wants to say, "Oh gosh, it would be so easy to have [a commercial digital textbook]." ... [Using open sources] still takes so much extra time and effort on my part that I could see where it would be ... enticing to people... . (i)n our district, because of the way we are, and because of the amount of effort we put into using technology from the get-go, all of us think it would be a waste of money. I'm sure we all would!

While the lower cost of open resources can be compelling, open textbooks have associated costs, including time and training. Once districts have invested considerable time, effort, and money in open textbooks, they may never go back to commercial textbooks. However, the resources required to make the switch from commercial to open textbooks may keep districts from adopting or successfully implementing open textbooks.

Access. Interviewees included increased access among the advantages of online textbooks. Dana noted that students "have no excuse for not doing the homework [because] it's online." Bailey pointed out, "[S]o many kids leave; they're on vacation, and they need that easy access." Teachers mentioned access not only to the book but to other resources online. Dana specified, "There's access to links that the kids can click on. They really like that. And so it's easier-it's more time-effective than [the teacher] playing YouTube videos in class." Eddie praised the open textbook for using "a variety of images and videos in addition to the actual text." 
Independent learning. Two interviewees anticipated that the open textbooks would promote student independence, but none reported observing this. Eddie made a specific application: "As a school we are moving toward mastery-learning, so students will be working at their own pace, and using the one-toone will definitely be helpful with that." Bailey shared a similar enthusiasm: "I'm excited to use this next year because I really want to stress this independent learning."

Disadvantages. Most of the disadvantages of the open textbooks mentioned by interviewees related to online aspects of the textbook. Some, like Chris, noted ongoing problems with links: "The links don't work all the time ... maybe they work with Chromebooks, but they don't work with iPads.” Eddie's problem resolved itself: "Linking it at first was tough-I linked things wrong ... . But now they hit the link just fine and it's not a problem." Another challenge mentioned was a lack of home internet access for some students:

I live in a school district in a town where not everybody has internet at home. . . . Now we have printed versions of [the open books], but [with] the printed versions, of course, you don't get to use the links, so you don't get to watch the videos. (Chris)

Alex's only complaint dealt with careless use:

The only thing I've really had an issue with is that if someone doesn't log out or log in, then somebody can ... make edits, not necessarily edits to the book, but they can change my highlighting and they can change my notes."

In addition to the challenges associated with technology, some requested more teacher support. Bailey emphasized the need for a teacher's manual for each textbook: "Especially one that could even highlight the extra activities, and an answer key-things like that. I think that would be helpful.” Bailey also suggested an assessment bank, "Because sometimes writing your tests-it's just nice to see those examples of how to assess your kids, and it doesn't have to be formal” (Bailey). Survey results also indicated needs for teacher support.

\section{Discussion}

This study examined outcomes of open textbook use, including effects on classroom practice. Most teachers surveyed reported some changes to classroom practice after adopting an open textbook, primarily related to the online textbook format with its capacity to make changes. Teachers for whom the format was the main difference might have found their classroom practice largely the same with an open or non-open online textbook. Others found their practice was affected primarily by the openness of the textbook: the ability to revise, adapt, remix, add links, and update the text from year-to-year. The effects of openness could not be entirely separated from format considerations. 


\section{Open Textbooks}

Three-fourths of participants preferred the open to previous non-open textbook, and respondents indicated in open-ended questions and interviews that the benefit they liked most was being able to revise and adapt it for their needs. As in previous studies (de los Arcos et al., 2016; Kimmons, 2015), participants rated open textbooks higher than non-open textbooks for various quality measures. Teachers who had been using insufficient numbers of outdated textbooks appreciated that open textbooks could be updated frequently and provided to each student at a low cost. Along with the strengths, participants suggested ways the open texts could be even more useful to them: (a) additional teacher support, (b) specific differentiation strategies, (c) improved alignment to assessments, and (d) better support for students above or below grade level.

The most common difficulties participants pointed out related to technology. Multiple participants reported problems with broken links-a minor irritation for some and a major hassle for others. Poor links and limited access can be remedied by providing students with print versions of open textbooks, an option that has delivered student outcomes comparable to or better than outcomes for students using traditional textbooks (Robinson et al., 2014). However, print versions need to be reprinted as they are updated, cannot be linked to content from other resources, and may cost more than electronic versions. As print versions of open textbooks do not provide all the benefits of online versions, study participants who reported using print-only versions of their open textbooks preferred the non-open textbooks that they previously used. Due to interactivity of openness and online format, the full benefits of open textbooks can be realized only where students have ready access to reliable internet service and electronic devices - a significant disadvantage to students in rural or low socio-economic communities. Also, open textbooks must be designed to work effectively on multiple platforms so that students with tablets have the same access to materials as students using Chromebooks, laptops, or desktop computers.

We had initially expected some teachers to make ongoing revisions of their textbooks throughout the school year, but interviewees indicated they saved revising and adapting for the summer months. They were too busy to make changes during the school year, and even simple revisions were complicated to share with students. Changing a version already published and shared might require students to download a new version of the textbook each time changes were made. Thus we recommend that administrators work with teachers to determine how frequently textbooks should be revised and to arrange time, training, and compensation for teachers to do so. The finding that teachers changed open textbooks only during the summer shows they were adapting the text to local, not individual student needs. Open online textbooks may facilitate differentiation with multiple ways of approaching material—linking to audio, video, and interactive resources — but survey and interview responses did not represent teachers providing customized versions of the textbook to individual students or small groups.

\section{Open Practices}

We were particularly concerned with whether using open textbooks would increase classroom practices related to openness (e.g., revising and adapting the textbook and collaborating with colleagues or students; 
cf. Kimmons, 2016). Conversely, our findings showed slight decreases in these areas. Survey respondents reported having revised or adapted their previous textbook in more lessons than they altered the open one, but these findings may involve a definitional issue: The open textbook can be directly revised and adapted, while the non-open one cannot. Thus revisions and adaptations to non-open textbook material were not likely textbook changes as facilitated by open textbooks. Furthermore, revisions made to open textbooks remained, whereas teachers were perpetually dealing with non-open textbook inadequacies. Though advocates might consider a decrease in the amount of revising and adapting as an adverse effect, teachers consider less revising and adapting as an advantage. Survey and interview responses indicated that the open textbook required less adaptation because it was better suited to teachers' needs.

Interview data indicated that strong collaboration during the process of revising and adapting an open textbook increased teacher satisfaction. But respondents reported decreased collaboration with colleagues and students after these procedures, a decrease unexplained by the data. The change was small enough to be attributed to a decrease in perceived need to use supplemental materials. Also earlier collaboration may have been for purposes other than selecting or adapting instructional materials. Though not reporting significant changes related to specific open practices, respondents did praise their open textbooks and value their openness.

\section{Future Research}

Future studies that might build upon this work should further explore not simply whether OER influence open practices but specifically how OER might be leveraged to change practices. They also might explore differences between OER and how specific elements of different types of OER might empower pedagogical shifts over others (e.g., flexibility of a discrete learning object vs. comprehensiveness of a textbook). Throughout most of the literature, OER adoption or cost savings are treated as end goals, but ideally we believe that improved student learning and improved pedagogies should be a driving goal of OER research moving forward. So, future studies might ask questions like: (a) what elements of OER better influence changes in pedagogy, (b) how do teachers interact differently with OER in different formats, and (c) how can OER be used as a catalyst for rethinking and restructuring classroom practices as part of larger innovative initiatives?

\section{Conclusion}

Three main findings were contributed by this study: (a) open practices of collaboration and revision did not increase after open textbooks were adopted, (b) participants preferred their open science textbook to their previous, non-open counterpart; and (c) the effects of online format were interactive with the effects of openness.

While one potential benefit of open textbooks is to increase open practices (e.g., collaboration, revision/adaptation of materials; Kimmons, 2016), in this study these open practices did not increase after 
open textbooks were adopted. Teachers collaborated in initial revising and adapting of open textbooks, but having done so, they were generally happy with the textbooks and postponed further revisions for summer. Among this sample, the use of open textbooks may have alleviated the need for continual textbook adaptation, thus mitigating a theoretical openness benefit.

Three-fourths of teachers in this study preferred their open science textbook to their previous textbook. Participants' positive perception of the open textbooks seemed to correlate with their involvement in designing their open textbooks. Participants had designed their textbooks according to what they needed and wanted-accuracy, relevance, clarity, concision, and alignment with state standards-which translated into high perceptions of quality. These findings suggest that teachers may be more satisfied with a textbook they help design than with a textbook designed by others.

In this study, the effects of online format and openness could not be disengaged. The most commonly cited changes to open books, such as adding in or linking to other resources, could be attributed to a combination of openness and online format. The data suggested that open textbooks are most effective when they are online, with students and teachers having reliable home and school access to internet service and electronic devices.

This study was undertaken to go beyond theoretical discussions of perceived benefits to examine real practices and outcomes for teachers and students. Results showed that teachers were more concerned with practical than idealistic considerations. Teachers want textbooks that meet student needs, and while open textbooks may do so better than non-open textbooks, openness itself may not be high on teachers' and students' lists of needs.

\section{Acknowledgements}

The authors would like to thank Cassidy Hall and the Doceo Center for Innovation + Learning at the University of Idaho for their participation in this project. 


\section{References}

Baker, A., Asino, T., Xiu, Y., \& Fulgencio, J. L. (2017). Logistical issues with OER initiative in a K-12 environment. In M. Mills \& D. Wake (Eds.), Empowering learners with mobile open-access learning initiatives (pp. 125-146). Chicago: IGI Global. doi:10.4018/978-1-5225-2122-8

Banilower, E. R., Smith, P. S., Weiss, I. R., Malzahn, K. A., Campbell, K. M., \& Weis, A. M. (2013). Report of the 2012 national survey of science and mathematics education. Chapel Hill, NC: Horizon Research, Inc.

Bliss, T., \& Patrick, S. (2013). OER state policy in K-12 education. iNACOL. Retrieved from http://www.inacol.org/resource/oer-state-policy-in-k-12-education-benefits-strategies-andrecommendations-for-open-access-open-sharing/

Butcher, N., \& Wilson-Strydom, M. (2008). Technology and open learning: The potential of open education resources for K-12 education. In J. Voogt \& G. Knezek (Eds.), International handbook of information technology in primary and secondary education (pp. 725-745). Boston, MA: Springer. doi:10.1007/978-0-387-73315-9

Charmaz, K. (2006). Constructing grounded theory: A practical guide through qualitative analysis. Thousand Oaks, CA: Sage Publications.

CK-12 Foundation. (2017). Our mission. Retrieved from www.ck12.org/

Common Core State Standards Initiative. (2016). Standards in your state. Retrieved from http://www.corestandards.org/standards-in-your-state/

de los Arcos, B., Farrow, R., Pitt, R., Weller, M., \& McAndrew, P. (2016). Adapting the curriculum: How $\mathrm{K}-12$ teachers perceive the role of open educational resources. Journal of Online Learning Research, 2(1), 23-40. Retrieved from https://www.learntechlib.org/primary/p/151664/

Hilton III, J., Larsen, R., Wiley, D., \& Fischer, L. (2016). Substituting open educational resources for commercial curriculum materials: Effects on student mathematics achievement in elementary schools. Manuscript submitted for publication.

K12 Handhelds. (2015). K-12 OER collaborative implementation study final report December 4, 2015. Retrieved from http://www.k12opened.com/blog/wp-content/uploads/K12HH-Final-ReportDec-2015.pdf

Kimmons, R. (2014). Developing open education literacies with practicing K-12 teachers. The International Review of Research in Open and Distributed Learning, 15(6). doi:10.19173/irrodl.v15i6.1964 
Kimmons, R. (2015). OER quality and adaptation in K-12: Comparing teacher evaluations of copyrightrestricted, open, and open/adapted textbooks. The International Review of Research in Open and Distributed Learning, 16(5). doi:10.19173/irrodl.v16i5.2341

Kimmons, R. (2016). Expansive openness in teacher practice. Teachers College Record, 118(9). Retrieved from http://www.tcrecord.org.erl.lib.byu.edu/library/

Merriam, S. B. (2009). Qualitative research: A guide to design and implementation (3rd ed.). San Franscisco, CA: Jossey-Bass.

Office of Educational Technology. (nd). Open education. Retrieved from http://tech.ed.gov/open/

Polikoff, M. S. (2015). How well aligned are textbooks to the common core standards in mathematics? American Educational Research Journal, 52, 1185-1211. doi:10.3102/0002831215584435

Remillard, J. T. (2005). Examining key concepts in research on teachers' use of mathematics curricula. Review of Educational Research, 75(2), 211-246. doi:10.3102/00346543075002211

Robinson, T. J., Fischer, L., Wiley, D., \& Hilton, J. (2014). The impact of open textbooks on secondary science learning outcomes. Educational Researcher, 43(7), 341-351.

doi:10.3102/0013189x14550275

Stern, L., \& Roseman, J. E. (2001). Textbook alignment. The Science Teacher, 68(7). Retrieved from https://search.proquest.com/openview/ad5751dba9c5118d7eb1bf3ccc2622c3/1?pqorigsite $=$ gscholar $\& \mathrm{cbl}=40,590$

Taylor, J. A., Getty, S. R., Kowalski, S. M., Wilson, C. D., Carlson, J., \& Van Scotter, P. (2015). An efficacy trial of research-based curriculum materials with curriculum-based professional development. American Educational Research Journal, 52(5), 984-1017. doi:10.3102/0002831215585962

The Boston Consulting Group. (2013). The open education resources ecosystem: An evaluation of the OER movement's current state and its progress toward mainstream adoption. Retrieved from http://www.hewlett.org/library/the-open-education-resources-ecosystem/

Tonks, D., Weston, S., Wiley, D., \& Barbour, M. (2013). “Opening” a new kind of school: The story of the Open High School of Utah. The International Review of Research in Open and Distance Learning, 14(1), 255-271. doi:10.19173/irrodl.v14i1.1345

UNESCO. (2016). What are open educational resources (OERs)? Retrieved from http://www.unesco.org/new/en/communication-and-information/access-to-knowledge/openeducational-resources/what-are-open-educational-resources-oers/ 
U.S. Department of Education. (2015). U.S. Department of Education launches campaign to encourage schools to \#GoOpen with educational resources [Press Release]. Retrieved from http://www.ed.gov/news/press-releases/us-department-education-launches-campaignencourage-schools-goopen-educational-resources

Wiley, D., Hilton, III, J., Ellington, S., \& Hall, T. (2012). A preliminary examination of the cost savings and learning impacts of using open textbooks in middle and high school science classes. International Review of Research in Open and Distance Learning, 13(3), 262-276. Retrieved from http://www.irrodl.org/index.php/irrodl/article/view/1153/2256

Wiley, D., Webb, A., Weston, S., \& Tonks, D. (2017). A preliminary exploration of the relationships between student-created OER, sustainability, and students' success. The International Review of Research in Open and Distributed Learning, 18(4). doi:10.19173/irrodl.v18i4.3022

\section{Athabasca University}

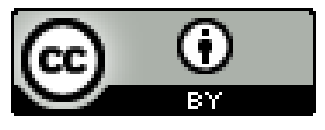

